\title{
The influence of selected socio-demographic variables on symptoms occurring during the menopause
}

\author{
Marta Makara-Studzińskaํ, Karolina Kryś-Noszczyk ${ }^{1}$, Grzegorz Jakiel² \\ ${ }^{1}$ Department of Applied Psychology, Medical University of Lublin, Poland \\ ${ }^{2}$ First Clinic of Obstetrics and Gynecology, Postgraduate Medical Education Centre in Warsaw, Poland
}

\begin{abstract}
Introduction: It is considered that the lifestyle conditioned by socio-demographic or socio-economic factors determines the health condition of people to the greatest extent. The aim of this study is to evaluate the influence of selected socio-demographic factors on the kinds of symptoms occurring during menopause.

Material and methods: The study group consisted of 210 women aged 45 to 65 , not using hormone replacement therapy, staying at healthcare centers for rehabilitation treatment. The study was carried out in 2013-2014 in the Silesian, Podlaskie and Lesser Poland voivodeships. The set of tools consisted of the authors' own survey questionnaire and the Menopause Rating Scale (MRS).

Results: The most commonly occurring symptom in the group of studied women was a depressive mood, from the group of psychological symptoms, followed by physical and mental fatigue, and discomfort connected with muscle and joint pain. The greatest intensity of symptoms was observed in the group of women with the lowest level of education, reporting an average or bad material situation, and unemployed women.

Conclusions: An alarmingly high number of reported psychological symptoms in the group of menopausal women was observed, and in particular among the group of low socio-economic status. Career seems to be a factor reducing the risk of occurrence of psychological symptoms. There is an urgent need for health promotion and prophylaxis in the group of menopausal women, and in many cases for implementation of specialist psychological assistance.
\end{abstract}

Key words: menopause, lifestyle, education, material situation.

\section{Introduction}

It is thought that the socio-economic factors which shape a pro-health or anti-health attitude and at the same time create the lifestyle of a given individual have a significant influence on the health of both individuals and the whole population. This group of factors includes the material situation, social status, level of education and social support. Poverty and a low level of education most often are responsible for inequalities in health. Individuals of a low socio-economic status in their own opinion have worse health, more often engage in behaviors risky for health, and have impeded access to healthcare institutions. Social support in the human living environment is considered to be a significant factor for shaping pro-health attitudes and preventing the pathogenic influence of potential stress factors.

The World Health Organization (WHO) suggests that at present depressive disorders constitute the fourth most serious health problem in the world, and in 2020, they will become the second most serious problem after ischemic heart disease [1], or they will be placed second by 2030 [2]. Depressive disorders in the course of chronic diseases are often diagnosed in the course of the metabolic syndrome and osteoporosis [3], i.e. diseases characteristic for the menopause period in women.

The perimenopause stage occurs in women in Poland on average between age 47 and 51 . Together with the postponement of the occurrence of the last period, the other conventional stages are postponed [4]. While numerous changes in the bio-psychophysical functioning of women occur, the most bothersome symptoms are psychological, somatic-vegetative and/or genitourinary symptoms.

Symptoms of discomfort connected with the pain of muscles and joints often intensify during the menopause and are connected with the involutional changes. Therefore, they can be an accompanying symptom in the course of osteoporosis, osteoarthritis, degenerative disc disease or other complaints with the character of involutional-proliferative changes of the motor system.

Women living on the African continent reported the occurrence of symptoms of discomfort connected with

Corresponding author: Professor Marta Makara-Studzińska, Department of Applied Psychology, Medical University of Lublin, 15 W. Chodźki St., 20-093 Lublin, phone: +48 8144866 00, fax: +48 8144866 00, e-mail: mmakara@go2.pl

To cite this article: Makara-Studzińska M, Kryś-Noszczyk K, Jakiel G. The influence of selected socio-demographic variables on symptoms occurring during the menopause. Prz Menopauzalny 2015; 14: 20-26.

Submitted: 9.09.2014; Accepted: 18.11.2014. 
the pain of muscles and joints in $59 \%$ to $88 \%$ of the cases studied in Nigeria $[5,6]$, to $90 \%$ of the cases in the group of women from Egypt [7]. In South America, discomfort connected with the pain of muscles and joints was reported by up to $84 \%$ of the studied women in Ecuador [8]. In North America, the percentage of women reporting the symptoms was up to $80 \%$ of the studied women in the USA [9]. In Australia, the percentage of women suffering from complaints of the motor system was up to $40 \%$ of the studied women [10]. In studies conducted in Asia the symptoms were noted in 33\% to $77 \%$ of women studied in India [11]. A review of European reports showed that in Italy the symptoms were reported by $31 \%$ of the studied women [7].

The next important symptom was depressive mood, from the subscale of psychological symptoms. The whole group of psychological symptoms may occur against the background of depressive disorders.

Many experts think that the depressive disorders in menopausal women are most often connected with psycho-sociological factors. In reference to the influence of socio-economic factors on the risk of occurrence of depressive disorders, residence in urban areas, lower monthly incomes and lower education have an effect [12].

The highest frequency of occurrence of psychological problems in the group of menopausal women was observed in a study from Pakistan, where $96 \%$ of the studied women reported the symptoms [13], or in a study from China, where $90 \%$ of respondents reported the occurrence of psychological symptoms [14].

However, attention should be paid to the fact reported in the literature that not all cognitive and emotional disorders have an environmental background and some of them can be proved to have a genetic background [15].

Freeman and Sherif found in 2007 that the following factors affect the occurrence of vasomotor symptoms: climate, diet, lifestyle, functions which the women have and their attitude towards the aging process [16].

In a study of 8373 women conducted in twelve countries in Central America, the occurrence of hot flashes in over $50 \%$ of women was observed. Greater intensity of the feeling of hot flashes was connected with a lower level of education and additional occurrence of psychological problems as well as urogenital dysfunctions [17].

In studies from Seattle it was found that the occurrence of, among other things, hot flashes in women in perimenopausal age is connected with sleep disorder, stress, depressive disorders and experiencing muscular and joint pain [18]. In the Penn Ovarian Aging study, hot flashes were associated with sleep disorders, which can be explained by the domino hypothesis, i.e. the decreased mood in women during the daytime due to awakenings and additionally the occurrence of depressive disorders against this background [19].
The aim of the study is to evaluate the influence of age, material situation, level of education and type of career on the kind of symptoms occurring during the menopause.

\section{Material and methods}

In November 2013, the organization of the area to conduct the studies began, after obtaining a positive opinion for the research project from the Bioethics Committee by the Medical University of Lublin, resolution number KE - 0254/269/2013 of 28 November 2013. The following healthcare centers were formally invited to co-operate: 1) NZOZ Centrum Opieki i Rehabilitacji "Zdrowie" S.C. [Non-Public Healthcare Institution - Center of Care and Rehabilitation "Zdrowie" Civil Partnership], Częstochowa; 2) NZOZ Sanatorium Uzdrowiskowe [Non-Public Healthcare Institution Spa Sanatorium], Gołdap; 3) 20. Wojskowy Szpital Uzdrowiskowo-Rehabilitacyjny SPZOZ $\left[20^{\text {th }}\right.$ Military Spa and Rehabilitation Hospital Independent Public Healthcare Institution], Krynica Zdrój.

After obtaining formal written permission from the Management Staff of the above centers, the study began in December 2013. It was completed in March 2014.

All respondents, before completing the questionnaire, were informed about the aim of the study and anonymity of answers. They were made familiar with the instructions for completing the questionnaires and ensured that the material would be used for scientific purposes.

The respondents also completed forms with the patient's informed consent to participation in the study, in accordance with the documentation based on which the project of the study obtained the positive opinion of the Bioethics Committee.

Women aged 45-65 not using hormone replacement therapy and staying at healthcare centers for rehabilitation treatment, who were willing to take part in the study and provided written consent, were eligible for inclusion in the study. During the first day of stay at the healthcare center, questionnaires were handed in to women; in compliance with the principle of anonymity, women returned the questionnaires to specially marked boxes in the centers. Three hundred questionnaires were given out, from which 212 were returned; 210 correctly completed questionnaires were subjected to further analysis. The return rate was $70.67 \%$.

The questions were adjusted on the basis of merit to the cognitive abilities of the study group. The set of research tools consisted of:

- the authors' own survey questionnaire,

- the Menopause Rating Scale (MRS).

The questions in the authors' own survey questionnaire were of multiple choice and half-open form, which allowed for subjective and spontaneous answers. 
The Menopause Rating Scale was developed at the beginning of the 1990s by Professor Heinemann from the Center of Epidemiology and Health Research in Berlin [20, 21]. The first use of the scale dates back to 1992, when the symptoms of menopause were documented and their changes during the treatment were observed [22]. In 1996, a randomized study of the representative group of 689 women aged 40-60 was carried out in Germany, and based on the results, an evaluation of the scale was conducted [23]. The scale is available in 25 languages.

The Polish version was used in the study after receiving the author's permission. At present the scale is commonly used to assess the symptoms of menopause among women of various nationalities, evaluating sleeplessness, sleep disorders [24] or the effect of using hormone replacement therapy. The currently available scientific evidence indicates the high methodological quality of the MRS to measure and compare the symptoms of menopause in the area of the quality of life of aging women in various regions of the world and the high reliability of the scale [20].

The tool is characterized by the ease of understanding for respondents and the clarity of questions. It contains 11 symptoms of menopause (hot flashes and sweating; heart problems; sleep problems; depressive mood; irritability; anxiety; physical and mental fatigue; sexual problems; bladder problems; vaginal dryness; discomfort connected with joints and muscles) whose intensity should be marked on the axis of the 5 categories: no symptom, mild, moderate, marked and severe. The respondent ensures subjective perception of symptoms by marking 1 of 5 possible fields. The total result of MRS is from 0 (no symptom) to 44 points (the highest grade of complaints of symptoms), and 11 symptoms were divided as follows:

- psychological symptoms (depression, irritation, anxiety and fatigue): from 0 to 16 points - questions 4 , $5,6,7$,

- somato-vegetative symptoms (sweating/hot flashes, heart palpitations, sleep disorders and muscular complaints): from 0 to 16 points - questions 1, 2, 3, 11,

- urogenital symptoms (sexual problems, urological problems and vaginal dryness): from 0 to 12 points questions 8, 9, 10.

The results were statistically analyzed. The values of the analyzed measurable parameters were presented using the average value and standard deviation, the immeasurable parameters were presented using frequencies and percentage. For quality characteristics to detect the existence of differences between the compared groups $\chi^{2}$ test was used. To test the normality of the variables in the study groups the Shapiro-Wilk normality test was performed. To examine differences between two groups non-parametric Mann-Whitney $U$ test was used and for more than two groups test ANOVA, or Kruskal-Wallis test was used. The level of significance was $p<0.05$, indicating the existence of significant differences or relationships. Database and statistical tests were carried out on the basis of computer software Statistica 9.1 (StatSoft, Poland).

\section{Results}

In the group of 210 studied women, those aged 45-50 made up the highest percentage (39.05\%), then women aged 51-55 (25.24\%), women aged 56-60 (20.48\%), and the least numerous group were women aged over 60 (15.24\%). Unequal number of women surveyed in each age group constitute a restriction for testing, but using appropriate statistical tests, it is possible to obtain reliable test results.

More than half (53.33\%) of the studied women lived in a district town, $27.14 \%$ in municipalities, and $19.52 \%$ in the provincial capital.

The majority of women (59.05\%) reported an average financial situation, while $26.19 \%$ described their financial situation as good, $7.14 \%$ as quite bad, $4.76 \%$ as very good, and $2.86 \%$ as bad.

More than half of those studied reported having a secondary education (52.86\%). Next there was vocational education (20.48\%), higher education (15.71\%), postgraduate education (7.62\%), and primary education (3.33\%).

The majority of women were working (66.19\%), $15.71 \%$ were retired, $10.95 \%$ had disability pension, while $7.14 \%$ were unemployed. Among all women, $35.24 \%$ were white-collar workers, $32.86 \%$ were manual workers, and $31.90 \%$ were not working.

The mean value of the sum of the points in the MRS was 14.95 , and the standard deviation was 8.60 .

The highest frequency of occurrence of symptoms was observed in the case of depressive mood (82.86\%), then discomfort connected with joints and muscles (82.38\%) and physical and mental fatigue (82.38\%). A very often occurring symptom was the feeling of irritation (81.90\%). Detailed results are presented in Table I.

Statistically significant differences were observed in the intensity of "hot flashes and sweating" between the age groups $(p=0.012)$. The differences concern groups I and II (between the age group 45-50 years and the group 51-55 years). Younger women (aged 45-50) achieved the mean result of $M=1.05$, and the women aged 51-55 on average $M=1.64$, i.e. the symptoms increased with the age of the studied women.

The lowest intensity of hot flashes occurs in groups I and IV, and the highest among women aged 51-55 and 56-60. No statistically significant differences were observed between groups I-III, II-III and I-IV.

In the case of the "heart problems", statistically significant differences were observed between groups I-II and I-IV $(p=0.002)$. No statistically significant differences were observed between groups I-III and II-III. Wom- 
en aged 45-50 obtained the mean result of $M=0.76$, women aged 51-55 on average $M=1.28$, whereas those aged over 60 obtained on average $M=1.34$. The symptoms significantly increased with age.

Also statistically significant differences were noted in intensity of bladder problems $(p=0.022)$ and discomfort connected with muscles and joints $(p=0.003)$.

In the case of bladder problems, the differences concern groups I-II. Women aged 45-50 obtained the mean result of $M=0.68$, and women aged 51-55 on average $M=1.15$. In the case of other age groups, no statistically significant differences were noted.

There were statistically significant differences in the intensity of discomfort connected with muscles and joints comparing groups I-III and I-IV. Women aged 45-50 obtained the mean result of $M=1.41$, women aged 56-60 on average $M=2.07$, those aged over 60 on average $M=2.19$. In the case of other age groups, no statistically significant differences were noted. The detailed results are presented in Table II.

Comparing two groups of financial situation (very good/good and average/bad) in reference to the results of the MRS and its subscales, all differences turned out to be statistically significant. The greatest intensity of symptoms in the MRS were noted in the case of women whose financial situation was average or bad (Table III).

Statistically significant differences were also observed when comparing the three groups of women depending on the level of education and the result in the MRS subscales. The differences in the MRS total score concern groups I-II (persons with primary education, vocational education and secondary education) and I-III (persons with primary education, vocational education and higher education). The highest MRS score, i.e. the
Tab. I. Structure of symptoms' occurrence

\begin{tabular}{lcc}
\hline Symptoms & $n$ & $\%$ \\
\hline Hot flashes, sweating & 144 & 68.57 \\
\hline Heart problems & 131 & 62.38 \\
\hline Sleep problems & 162 & 77.14 \\
\hline Depressive mood & 174 & 82.86 \\
\hline Irritation & 172 & 81.90 \\
\hline Anxiety & 160 & 76.19 \\
\hline Physical and mental fatigue & 173 & 82.38 \\
\hline Sexual problems & 137 & 65.24 \\
\hline Bladder problems & 112 & 53.33 \\
\hline $\begin{array}{l}\text { Vaginal dryness } \\
\text { Discomfort connected with joints } \\
\text { and muscles }\end{array}$ & 139 & 66.19 \\
\hline
\end{tabular}

greatest intensity of the symptoms, was noted in women with the lowest education $(M=18.14)$. The detailed results are presented in Table IV.

The analysis of the results of the MRS compared to the kind of performed work shows that all differences are statistically significant. The differences in the MRS total score concern groups I-III (white-collar women and non-working women). The highest MRS score, i.e. the greatest intensity of symptoms, was observed in women who did not work $(M=17.93)$. Statistically significant differences for psychological symptoms were noted in groups I-III; i.e. in women who did not work, the intensity of psychological symptoms was greater $(M=$ 7.16) compared to the white-collar women $(M=5.15)$.

Tab. II. Occurrence of symptoms in individual age groups of studied women

\begin{tabular}{|c|c|c|c|c|c|c|c|c|c|c|c|}
\hline \multirow[t]{2}{*}{ Symptoms } & \multicolumn{2}{|c|}{$\begin{array}{l}\text { I) } 45-50 \\
\text { years }\end{array}$} & \multicolumn{2}{|c|}{$\begin{array}{l}\text { II) } 51-55 \\
\text { years }\end{array}$} & \multicolumn{2}{|c|}{$\begin{array}{l}\text { III) } 56-60 \\
\text { years }\end{array}$} & \multicolumn{2}{|c|}{$\begin{array}{l}\text { IV) Over } \\
60 \text { years }\end{array}$} & \multicolumn{2}{|c|}{$\begin{array}{l}\text { Analysis of } \\
\text { differences }\end{array}$} & \multirow{2}{*}{$\begin{array}{c}\text { Differences } \\
\text { between } \\
\text { groups }\end{array}$} \\
\hline & $M$ & $S D$ & $M$ & $S D$ & $M$ & $S D$ & $M$ & $S D$ & $H$ & $p$ & \\
\hline Hot flashes, sweating & 1.05 & 1.08 & 1.64 & 1.19 & 1.44 & 1.05 & 1.09 & 0.96 & 10.878 & 0.012 & $|-| \mid$ \\
\hline Heart problems & 0.76 & 0.92 & 1.28 & 0.99 & 1.05 & 1.07 & 1.34 & 0.94 & 14.556 & 0.002 & I-II, I-IV \\
\hline Sleep problems & 1.28 & 1.16 & 1.79 & 1.29 & 1.70 & 1.17 & 1.72 & 1.08 & 8.112 & 0,044 & - \\
\hline Depressive mood & 1.48 & 1.21 & 1.83 & 1.22 & 1.72 & 0.98 & 1.53 & 0.98 & 4.100 & 0.251 & - \\
\hline Irritation & 1.43 & 1.12 & 1.64 & 1.11 & 1.77 & 0.92 & 1.38 & 1.04 & 5.124 & 0.163 & - \\
\hline Anxiety & 1.32 & 1.09 & 1.53 & 1.15 & 1.51 & 1.18 & 1.34 & 1.10 & 1.506 & 0.681 & - \\
\hline Physical and mental fatigue & 1.26 & 1.09 & 1.64 & 0.96 & 1.65 & 1.04 & 1.56 & 0.91 & 8.109 & 0.044 & - \\
\hline Sexual problems & 1.02 & 1.10 & 1.40 & 1.01 & 1.14 & 1.06 & 1.31 & 1.15 & 5.448 & 0.142 & - \\
\hline Bladder problems & 0.68 & 0.98 & 1.15 & 1.06 & 0.91 & 1.13 & 1.19 & 1.20 & 9.620 & 0.022 & $|-| \mid$ \\
\hline Vaginal dryness & 0.88 & 0.93 & 1.34 & 1.07 & 1.12 & 1.03 & 1.28 & 1.17 & 7.330 & 0.062 & - \\
\hline $\begin{array}{l}\text { Discomfort connected with } \\
\text { joints and muscles }\end{array}$ & 1.41 & 1.25 & 1.91 & 1.15 & 2.07 & 1.10 & 2.19 & 1.26 & 14.47 & 0.003 & I-III, I-IV \\
\hline
\end{tabular}


Tab. III. Material situation versus the Menopause Rating Scale (MRS) subscales

\begin{tabular}{|c|c|c|c|c|c|c|}
\hline \multirow[t]{2}{*}{ MRS } & \multicolumn{2}{|c|}{ Very good/Good } & \multicolumn{2}{|c|}{ Average/Bad } & \multicolumn{2}{|c|}{ Analysis of differences } \\
\hline & $M$ & $S D$ & $M$ & $S D$ & $Z$ & $P$ \\
\hline MRS & 11.92 & 7.09 & 16.31 & 8.88 & -3.310 & 0.001 \\
\hline Psychological symptoms & 4.62 & 3.17 & 6.71 & 3.85 & -3.629 & $<0.001$ \\
\hline Somato-vegetative symptoms & 4.74 & 3.25 & 6.10 & 3.31 & -2.656 & 0.008 \\
\hline Urogenital symptoms & 2.57 & 2.09 & 3.50 & 2.75 & -2.078 & 0.038 \\
\hline
\end{tabular}

Tab. IV. Education versus the Menopause Rating Scale (MRS) subscales

\begin{tabular}{|c|c|c|c|c|c|c|c|c|c|}
\hline \multirow[t]{2}{*}{ MRS } & \multicolumn{2}{|c|}{$\begin{array}{l}\text { I) Primary/ } \\
\text { Vocational }\end{array}$} & \multicolumn{2}{|c|}{ II) Secondary } & \multicolumn{2}{|c|}{$\begin{array}{l}\text { III) Higher/ } \\
\text { Postgraduate }\end{array}$} & \multicolumn{2}{|c|}{$\begin{array}{c}\text { Analysis } \\
\text { of differences }\end{array}$} & \multirow{2}{*}{$\begin{array}{c}\text { Differences } \\
\text { between } \\
\text { groups }\end{array}$} \\
\hline & $M$ & $S D$ & $M$ & $S D$ & $M$ & $S D$ & $F$ & $p$ & \\
\hline MRS & 18.14 & 7.72 & 13.89 & 7.97 & 14.10 & 10.07 & 4.680 & 0.010 & $|-| I,|-|||$ \\
\hline Psychological symptoms & 7.20 & 3.39 & 5.78 & 3.69 & 5.53 & 4.14 & 3.125 & 0.046 & $|-|||-|| \mid$, \\
\hline Somato-vegetative symptoms & 6.92 & 2.95 & 5.30 & 3.16 & 5.27 & 3.84 & 4.713 & 0.010 & $|-|||-|| \mid$, \\
\hline Urogenital symptoms & 4.02 & 2.62 & 2.81 & 2.32 & 3.31 & 2.99 & 3.881 & 0.022 & $|-| \mid$ \\
\hline
\end{tabular}

The somato-vegetative symptoms were most intense in the group of non-working women $(M=6.69)$ compared to women performing manual labor $(M=5.49)$ or white-collar women $(M=4.93)$. A similar tendency of intensity of symptoms occurred in the case of urogenital symptoms (Table V).

\section{Discussion}

Cross-sectional surveys conducted in 2005-2007 among healthy adult women - inhabitants of Poland's southern voivodeships ( $n=896$; age over 40 years) show that the most frequent reported complaints were irritation, hotness, sleep disorders and sudden changes of mood. The fewest women reported vaginal dryness [25]. Those results differ from the information obtained in the present study. In our study, the highest percentage of occurrence of symptoms was observed in the case of depressive mood (82.86\%), followed by discomfort connected with joints and muscles (82.38\%) and physical and mental fatigue (82.38\%). A very common symptom in the group of surveyed women was irritability $(81.90 \%)$. The results of this study are similar to recent data from the scientific literature of the world.

The results concerning the structure of the occurrence of the menopause symptoms are closest to the data reported by Joseph et al. [26] and da Silva et al. [27] referring accordingly to the women of the Indian and Brazilian population. The most often occurring symptoms in the Indian study using the MRS were discomfort connected with the pain of muscles and joints (85.4\%) and physical and mental fatigue, and the educated women reported considerably more symptoms, which was statistically significant. No statistically significant correlation was noted in the case of the number of reported symptoms and the age of the studied women or the kind of their employment [26], which considerably distinguishes this part of the study results and socio-demographic situation of the Polish and Indian women.

The situation in which better educated women reported more symptoms during the menopause was

Tab. V. Type of work versus the Menopause Rating Scale (MRS) subscales

\begin{tabular}{|c|c|c|c|c|c|c|c|c|c|}
\hline \multirow[t]{2}{*}{ MRS } & \multicolumn{2}{|c|}{$\begin{array}{c}\text { I) White-collar } \\
\text { work }\end{array}$} & \multicolumn{2}{|c|}{ II) Manual labor } & \multicolumn{2}{|c|}{ III) Not working } & \multicolumn{2}{|c|}{$\begin{array}{c}\text { Analysis } \\
\text { of differences }\end{array}$} & \multirow{2}{*}{$\begin{array}{c}\text { Differences } \\
\text { between } \\
\text { groups }\end{array}$} \\
\hline & $M$ & $S D$ & $M$ & $S D$ & $M$ & $S D$ & $F$ & $p$ & \\
\hline MRS & 12.81 & 7.90 & 14.36 & 8.02 & 17.93 & 9.18 & 6.825 & 0.001 & |-|II, ||-||| \\
\hline Psychological symptoms & 5.15 & 3.58 & 5.97 & 3.51 & 7.16 & 4.00 & 5.254 & 0.006 & $|-|||$ \\
\hline Somato-vegetative symptoms & 4.93 & 3.12 & 5.49 & 3.34 & 6.69 & 3.38 & 5.205 & 0.006 & |-III, II-III \\
\hline Urogenital symptoms & 2.73 & 2.45 & 2.90 & 2.24 & 4.07 & 2.90 & 5.723 & 0.004 & |-III, ||-|I| \\
\hline
\end{tabular}


also noted in the presented study results from Taiwan [28]. The opposite situation is observed in Poland, in light of the results of this study. The greatest intensity of symptoms is observed in the group of women with the lowest education. In European countries it is assumed that poverty and a low level of education are most often the reason for inequality in health.

The greatest intensity of symptoms in the MRS in this study was noted in the case of women whose financial situation was average or bad, in women with the lowest education and in women who did not work. These differences were statistically significant and such results are confirmed in the literature of the subject [27, 29-31].

Women in the post-menopausal stage who reported the intensity of symptoms in reference to the particular stages of experiencing the menopause were qualified for the study in Italy [7]. In most of the studied women - about $66 \%$ - pain symptoms occurred before the menopause and in half of the cases decreased during the menopause or stayed at a constant level. The symptoms of discomfort connected with joints and muscles in light of this study were rarer among women aged 4550 years $(70.73 \%)$, and most frequent in women aged 56-60 years (93.02\%), which may be connected with different age of entering the menopause in Italy and Poland and of the kind of work performed by the studied women. Unfortunately, no detailed information on the kind of work performed by the women is available from the Italian report.

Studies conducted in Malaysia proved the statistical significance and correlation between the general result in the scale of menopause symptoms and age [32]. In a study of 31 patients aged 47-62 years differing in numerous psychosocial factors a correlation between age and level of dejectedness [33] was also observed. The results of the present study do not show statistically significant differences between age and the level of dejectedness. Humeniuk et al. found that residence in rural areas is a factor increasing the risk of depressive disorders, which was not confirmed in this study [34].

In this study statistically significant differences were observed in the intensity of "hot flashes and sweating" between age groups of women. The intensity of symptoms significantly increases at the age of 51-55 compared to younger women - which indicates a mean age of women during the menopause transition, related to the severity of sleep disorders, excessive stress, depressive disorders $[35,36]$. According to the researchers, the severity of symptoms may also be associated with having lower education, urinary dysfunction - sex, prevalence of psychological symptoms [17], and also inhabiting in a distinctive climate, the use of diet, appropriate lifestyle, which features a woman fully in social life, family and her attitude to the aging process [16].

\section{Conclusions}

An alarmingly high number of reported psychological symptoms in the group of menopausal women, and in particular among the group of low socio-economic status, unemployed, with the basic level of education was observed.

What remains unclear is the relationship between selected socio-demographic variables and the occurrence of intensifying depressive disorder during menopause.

Emotional disorder during menopause is not willingly reported by women and an important symptom of the deteriorating woman's health.

Career seems to be a factor reducing the risk of occurrence of psychological symptoms.

There is an urgent need for health promotion and prophylaxis in the group of menopausal women, and in many cases of implementation of specialist psychological assistance.

\section{Disclosure}

Authors report no conflict of interest.

\section{References}

1. Cleare A. Choroba afektywna jednobiegunowa (depresja nawracająca). In: Psychiatria. Sedno. Wright P, Stern J, Phelan M. Vol. 1. Elsevier Urban \& Partner, Wroctaw 2008

2. Wittchen HU, Jacobi F. Size and burden of mental disorders in Europe a critical review and appraisal of 27 studies. Eur Neuropsychopharmacol 2005; 15: 357-376.

3. Mathers CD, Loncar D. Projections of global mortality and burden of disease from 2002 to 2030. PLoS Med 2006; 3: e442.

4. Pertyński T, Stetkiewicz T. Perimenopauza. W: Diagnostyka i terapia wieku menopauzalnego. Pertyński T (red.). Urban \& Partner, Wrocław 2004, pp. 313-316.

5. Chen R, Yu Q, Xu KH, et al. Survey on characteristics of menopause of Chinese women with the age of 40-60 years at gynecological clinic from 14 hospitals. Zhonghua Fu Chan Ke Za Zhi 2013; 48: 723-727 [Article in Chinese].

6. Gao HL, Lin SQ, Wei Y, et al. The effect of age and menopausal status on musculoskeletal symptoms in Chinese women aged 35-64 years. Climacteric 2013; 16: 639-645

7. Meriggiola MC, Nanni M, Bachiocco V, et al. Menopause affects pain depending on pain type and characteristics. Menopause 2012; 19 : 517-523.

8. Murray CJ, Lopez AD. Alternative projections of mortality and disability by cause 1990-2020: Global Burden of Disease Study. Lancet 1997; 349: 1498-1504.

9. Bromberger JT, Kravitz HM, Matthews K, et al. Predictors of first lifetime episodes of major depression in midlife women. Psychol Med 2009; 39 : 55-64.

10. Berecki-Gisolf J, Begum N, Dobson AJ. Symptoms reported by women in midlife: menopausal transition or aging? Menopause 2009; 16: 10211029.

11. Frey BN, Lord C, Soares CN. Depression during menopausal transition: a review of treatment strategies and pathophysiological correlates. Menopause Int 2008; 14: 123-128.

12. Ambler DR, Bieber EJ, Diamond MP. Sexual function in elderly women: a review of current literature. Rev Obstet Gynecol 2012; 5: 16-27.

13. Nisar N, Sohoo NA. Frequency of menopausal symptoms and their impact on the quality of life of women: a hospital based survey. J Pak Med Assoc 2009; 59: 752-756. 
14. Chen Y, Lin SQ, Wei Y, et al. Menopause-specific quality of life satisfaction in community-dwelling menopausal women in China. Gynecol Endocrinol 2007; 23: 166-172.

15. Bojar I, Raczkiewicz D, Wdowiak A, et al. The effect of prolactin and apolipoprotein $\mathrm{E}$ gene polymorphism on cognitive functions of menopausal women. Ginekol Pol 2014; 85: 131-139.

16. Freeman EW, Sherif K. Prevalence of hot flushes and night sweats around the world: a systematic review. Climacteric 2007; 10: 197-214.

17. Blümel JE, Chedraui P, Baron G, et al. A large multinational study of vasomotor symptom prevalence, duration, and impact on quality of life in middle-aged women. Menopause 2011; 18: 778-785.

18. Woods NF, Mitchell ES. Sleep symptoms during the menopausal transition and early postmenopause: observations from the Seattle Midlife Women's Health Study. Sleep 2010; 33: 539-549.

19. Joffe H, Soares CN, Thurston RC, et al. Depression is associated with greater objectively and subjectively measured sleep in women with vasomotor symptoms. Menopause 2009; 16: 671-679.

20. Heinemann K, Assmann A, Möhner S, et al. Reliability of the Menopause Rating Scale (MRS): Investigation in the German population. Zentralbl Gynakol 2002; 124: 161-163.

21. Heinemann K, Ruebig A, Potthoff P, et al. The Menopause Rating Scale (MRS) scale: a methodological review. Health Qual Life Outcomes 2004; 2: 45 .

22. Heinemann LA, Potthoff P, Schneider HP. International versions of the Menopause Rating Scale (MRS). Health Qual Life Outcomes 2003; 1: 28.

23. Hauser GA, Huber IC, Keller PJ, et al. Evaluation der klinischen Beschwerden (Menopause Rating Scale). Zentralbl Gynakol 1994; 116: 16-23.

24. Boral Ş, Borde T, Kentenich $\mathrm{H}$, et al. Migration and symptom reporting at menopause: a comparative survey of migrant women from Turkey in Berlin, German women in Berlin, and women in Istanbul. Menopause 2013; 20: 169-178.

25. Stachoń AJ. Ocena odczuwania wybranych objawów w zależności od fazy klimakterium i charakteru menopauzy. Prz Menopauzalny 2013; 12: 315-320.
26. Joseph N, Nagaraj K, Saralaya V, et al. Assessment of menopausal symptoms among women attending various outreach clinics in South Canara District of India. J Midlife Health 2014; 5: 84-90.

27. da Silva AR, d'Andretta Tanaka AC. Factors associated with menopausal symptom severity in middle-aged Brazilian women from the Brazilian Western Amazon. Maturitas 2013; 76: 64-69.

28. Cheng MH, Wang SJ, Wang PH, Fuh JL. Attitudes toward menopause among middle-aged women: a community survey in an island of Taiwan. Maturitas 2005; 52: 348-355.

29. Gharaibeh M, Al-Obeisat S, Hattab J. Severity of menopausal symptoms of Jordanian women. Climacteric 2010; 13: 385-394.

30. Lee $\mathrm{Y}, \mathrm{Kim} \mathrm{H}$. Relationships between menopausal symptoms, depression, and exercise in middle-aged women: a cross-sectional survey. Int J Nurs Stud 2008; 45: 1816-1822.

31. Olaolorun FM, Lawoyin TO. Experience of menopausal symptoms by women in an urban community in Ibadan, Nigeria. Menopause 2009; 16: 822-830.

32. Jahanfar SH, Abdul Rahim BA, Shah Reza BK. Age at menopause and menopausal symptoms among Malaysian women who were referred to a health clinic in Malaysia. Shiraz E-Med J 2006; 7: 3.

33. Walczak A, Wiśniewska B. Psychospołeczne aspekty funkcjonowania kobiet w okresie postmenopauzalnym - badania wstępne. Prz Menopauzalny 2012; 11: 474-477.

34. Humeniuk E, Bojar I, Owoc A, et al. Psychosocial conditioning of depressive disorders in post-menopausal women. Ann Agric Environ Med 2011; 18: 441-445.

35. Woods NF, Mitchell ES. Sleep symptoms during the menopausal transition and early postmenopause: observations from the Seattle Midlife Women's Health Study. Sleep 2010; 33: 539-549.

36. Joffe H, Soares CN, Thurston RC, et al. Depression is associated with greater objectively and subjectively measured sleep in women with vasomotor symptoms. Menopause 2009; 16: 671-679. 